\title{
The Complex Formation of Dibenzyl Sulfoxide with Various
}

\section{Proton Donors}

\author{
P. RUOSTESUO and J. KARJALAINEN
}

Department of Chemistry, University of Oulu, SF-90570 Oulu 57, Finland

The complex formation of dibenzyl sulfoxide with phenol, 1-naphthol, 2-naphthol, 2,2,2-trifluoroethanol, 2,2,2-trichloroethanol, 2,2,2-tribromoethanol, pyrrole, indole and carbazole has been studied by near infrared spectrophotometry in carbon tetrachloride at $288.15,298.15,308.15$ and $318.15 \mathrm{~K}$.

The results show the proton-accepting ability of dibenzyl sulfoxide to be smaller than that of dimethyl sulfoxide and greater than that of diphenyl sulfoxide toward all the $\mathrm{OH}$ and $\mathrm{NH}$ proton donors studied.

This paper is a part of our attempt to clarify systematically the complex formation ability of sulfonyl and sulfinyl compounds. The earlier results suggest a close similarity in the proton accepting behaviours of sulfones and sulfonamides and, correspondingly, of sulfoxides and sulfinamides. On the other hand, the complex formation ability of dimethyl sulfoxide is known to be relatively strong and that of diphenyl sulfoxide has been found to be half as great, as measured by the $K$ values. ${ }^{1,2}$ We have now extended our studies to the complex formation of dibenzyl sulfoxide with various $\mathrm{OH}$ and $\mathrm{NH}$ proton donors in carbon tetrachloride.

\section{EXPERIMENTAL}

Dibenzyl sulfoxide (a purum reagent from Fluka AG) was crystallized several times from absolute ethanol. Carbon tetrachloride for IR-spectroscopy (Fluka AG, Buchs, Switzerland) was dried and preserved above Union Carbide molecular sieves, Type 4 A, from Fluka AG.

The proton donors were commercial products, purified as described earlier. ${ }^{1-6}$

All spectra were recorded with a Beckman ACTA MIV spectrophotometer at 288.15, 298.15, 308.15 and $318.15 \mathrm{~K}$ in carbon tetrachloride solution. A quartz cell of $10-\mathrm{mm}$ path length was used. The temperature of the measuring and reference cells was kept constant to within $\pm 0.2^{\circ} \mathrm{C}$. The concentration of the proton donors was between 0.002 and $0.004 \mathrm{~mol} \mathrm{dm}^{-3}$ and the dibenzylsulfoxide was used in various amounts of excess depending on the proton donor. The cell in the reference beam contained the base in carbon tetrachloride at the same initial concentration as in the sample cell. Details of the apparatus and the methods have been reported previously. ${ }^{1}$

\section{RESULTS}

The equilibrium constants at different temperatures for the complex formation of dibenzyl sulfoxide with various proton donors are presented in Table 1 . The $K$ values were calculated from the absorbance values of the free $\mathrm{OH} / \mathrm{NH}$ group stretching band of the proton donor observed before $\left(A^{\circ}\right)$ and after $(A)$ the complex formation, using eqn. (1), where

$$
K_{11}=\frac{1-A / A^{\circ}}{A / A^{\circ}\left[C_{\mathrm{B}}^{\circ}-C_{\mathrm{A}}^{\circ}\left(1-A / A^{\circ}\right)\right]}
$$

$C_{\mathrm{B}}^{\circ}$ and $C_{\mathrm{A}}^{\circ}$ are the initial concentrations of proton acceptor and proton donor, respectively. The $K$ values, as well as the $\Delta H$ values and other quantities presented in Table 2, are mean values of 3-5 independent measurements. The standard error of the mean values is also given in Tables 1 and 2 . The $\Delta H$ values were obtained from the temperature dependence of the $K$ values and other thermodynamic quantities according to the normal therm $\rho$ dynamic relations.

For comparison Tables 3 and 4 contain the equilibrium constants $(K)$ at $298.15 \mathrm{~K}$, the complexation enthalpies $(\Delta H)$, and the wavenumber shifts $\left(\Delta \bar{v}_{\mathrm{OH}} / \Delta \bar{v}_{\mathrm{NH}}\right)$ for the complexes of dimethyl sulfoxide 
Table 1. Values of $K_{11} / \mathrm{dm}^{3} \mathrm{~mol}^{-1}$ for the complex formation of dibenzyl sulfoxide with various proton donors in carbon tetrachloride at different temperatures.

\begin{tabular}{|c|c|c|c|c|}
\hline Proton donor & $288.15 \mathrm{~K}$ & $298.15 \mathrm{~K}$ & $308.15 \mathrm{~K}$ & $318.15 \mathrm{~K}$ \\
\hline Phenol & $205 \pm 15$ & $145 \pm 12$ & 106 & $78.7 \pm 5.5$ \\
\hline 1-Naphthol & $272 \pm 20$ & $190 \pm 16$ & \pm 10 & $97.1 \pm 6.0$ \\
\hline 2-Naphthol & $307 \pm 16$ & $213 \pm 13$ & $151 \pm 10$ & $110 \pm 7$ \\
\hline 2,2,2-Tribromoethanol & $53.9 \pm 4.2$ & $41.3 \pm 3.3$ & $33.4 \pm 2.7$ & $26.1 \pm 1.9$ \\
\hline 2,2,2-Trichloroethanol & $63.4 \pm 5.2$ & $46.9 \pm 4.0$ & $35.3 \pm 3.1$ & $25.9 \pm 2.2$ \\
\hline 2,2,2-Trifluoroethanol & $141 \pm 12$ & $104 \pm 9$ & $77.0 \pm 7.0$ & $59.1 \pm 5.6$ \\
\hline Pyrrole & $12.7 \pm 1.0$ & $10.5 \pm 0.9$ & $8.76 \pm 0.80$ & $7.17 \pm 0.62$ \\
\hline Indole & $21.3 \pm 2.0$ & $17.2 \pm 1.7$ & $14.1 \pm 1.3$ & $12.1 \pm 1.1$ \\
\hline Carbazole & $30.9 \pm 2.3$ & $24.8 \pm 1.9$ & $19.8 \pm 1.4$ & $16.3 \pm 1.2$ \\
\hline
\end{tabular}

Table 2. Values of thermodynamic quantities $\Delta H, \Delta G^{\circ}$ and $\Delta S^{\circ}$ and the wavenumber shifts $\Delta \bar{v}_{\mathrm{OH}} / \Delta \bar{v}_{\mathrm{NH}}$ for the complex formation between dibenzyl sulfoxide and various proton donors in carbon tetrachloride.

\begin{tabular}{llccc}
\hline Proton donor & $\frac{-\Delta H}{\mathrm{~kJ} \mathrm{~mol}^{-1}}$ & \multicolumn{1}{c}{$\mathrm{kJ} \mathrm{mol}^{-1}$} & $\frac{-\Delta S^{\circ}}{\mathrm{J} \mathrm{mol}^{-1} \mathrm{~K}^{-1}}$ & $\frac{\Delta \bar{v}_{\mathrm{OH}} / \Delta \bar{v}_{\mathrm{NH}}}{\mathrm{cm}^{-1}}$ \\
\hline Phenol & $24.3 \pm 1.9$ & $12.34 \pm 0.20$ & $42.0 \pm 5.2$ & $342 \pm 2$ \\
1-Naphthol & $26.2 \pm 1.2$ & $13.00 \pm 0.21$ & $44.3 \pm 4.8$ & $369 \pm 2$ \\
2-Naphthol & $26.1 \pm 1.3$ & $13.29 \pm 0.15$ & $43.0 \pm 5.0$ & $359 \pm 2$ \\
2,2,2-Tribromoethanol & $18.1 \pm 0.9$ & $9.22 \pm 0.11$ & $29.9 \pm 3.3$ & $277 \pm 2$ \\
2,2,2-Trichloroethanol & $22.6 \pm 0.8$ & $9.54 \pm 0.20$ & $43.8 \pm 3.4$ & $283 \pm 2$ \\
2,2,2-Trifluoroethanol & $23.2 \pm 0.7$ & $11.50 \pm 0.25$ & $39.2 \pm 3.3$ & $285 \pm 2$ \\
Pyrrole & $14.4 \pm 0.9$ & $5.82 \pm 0.21$ & $28.7 \pm 3.8$ & $167 \pm 2$ \\
Indole & $14.5 \pm 0.8$ & $7.05 \pm 0.26$ & $24.9 \pm 3.6$ & $186 \pm 2$ \\
Carbazole & $16.4 \pm 1.2$ & $7.96 \pm 0.18$ & $28.2 \pm 4.6$ & $190 \pm 2$ \\
\hline
\end{tabular}

Table 3. Values of $K^{298}, \Delta H$ and $\bar{v}_{\mathrm{OH}} / \Delta \bar{v}_{\mathrm{NH}}$ for the complex formation of dimethyl sulfoxide with various proton donors in carbon tetrachloride.

\begin{tabular}{lllll}
\hline Proton donor & $K^{298}$ & $\frac{-\Delta H}{\mathrm{~kJ} \mathrm{~mol}^{-1}}$ & $\frac{\Delta \bar{v}_{\mathrm{OH}} / \Delta \bar{v}_{\mathrm{NH}}}{\mathrm{cm}^{-1}}$ & Ref. \\
\hline Phenol & 220 & 24.3 & 362 & 1 \\
1-Naphthol & 254 & 27.1 & 389 & 3 \\
2-Naphthol & 288 & 27.1 & 376 & 4 \\
2,2,2-Tribromoethanol & 48.1 & 21.3 & 296 & 7 \\
2,2,2-Trichloroethanol & 68.4 & 21.3 & 301 & 5 \\
2,2,2-Trifluoroethanol & 148 & 23.1 & 306 & 6 \\
Pyrrole & 16.5 & 15.6 & 185 & 6 \\
Indole & 21.9 & 16.9 & 203 & 6 \\
Carbazole & 31.2 & 17.4 & 210 & \\
\hline
\end{tabular}

with the same proton donors. ${ }^{1-7}$ The complex formation of dibenzyl sulfoxide with napthols has earlier been studied under quite different conditions ${ }^{8}$ and some isolated values have been published for phenol ${ }^{9}$ and indole. ${ }^{10}$

\section{DISCUSSION}

It is well known that sulfoxides act as electron donors in hydrogen bond formation and that their electron donating ability is much greater than that of sulfones. ${ }^{3,4,11-13}$ Among sulfoxides, the 
Table 4. Values of $K^{298}, \Delta H$ and $\Delta \bar{v}_{\mathrm{OH}} / \Delta \bar{v}_{\mathrm{NH}}$ for the complex formation of diphenyl sulfoxide with various proton donors in carbon tetrachloride.

\begin{tabular}{lllll}
\hline Proton donor & $\frac{K^{298}}{\mathrm{dm}^{3} \mathrm{~mol}^{-1}}$ & $\frac{-\Delta H}{\mathrm{~kJ} \mathrm{~mol}^{-1}}$ & $\frac{\Delta \bar{v}_{\mathrm{OH}} / \Delta \bar{v}_{\mathrm{NH}}}{\mathrm{cm}^{-1}}$ & Ref. \\
\hline Phenol & 61.4 & 20.3 & 298 & 2 \\
1-Naphthol & 77.9 & 23.1 & 321 & 3 \\
2-Naphthol & 89.8 & 23.4 & 315 & 4 \\
2,2,2-Tribromoethanol & 17.6 & 18.8 & 243 & 7 \\
2,2,2-Trichloroethanol & 22.1 & 18.8 & 247 & 5 \\
2,2,2-Trifluoroethanol & 48.6 & 21.0 & 250 & 6 \\
Pyrrole & 9.05 & 13.5 & 153 & 6 \\
Indole & 11.6 & 14.8 & 172 & 6 \\
Carbazole & 15.8 & 13.5 & 174 & \\
\hline
\end{tabular}

complex formation of dimethyl sulfoxide ${ }^{14,15}$ with various proton donors has been extensively studied, and to a lesser extent the complex formation of diphenyl sulfoxide. ${ }^{16-18}$ These studies have shown that the complex formation ability of dimethyl sulfoxide is greater than that of diphenyl sulfoxide, as do the results gathered from our earlier studies collected in Tables 3 and 4.

The results obtained here for the complex formation of dibenzyl sulfoxide with various proton donors seem to be in agreement with those reported earlier in the literature, ${ }^{9,10}$ i.e. the tendency of dibenzyl sulfoxide to form hydrogen-bonded complexes is a little smaller than that of dimethyl sulfoxide (Table 3). This finding is consistent with the tendency of the phenyl group to withdraw electrons, in contrast to the methyl group in dimethyl sulfoxide. Steric factors may further help to lower the ability of dibenzyl sulfoxide to form hydrogen-bonded complexes. Taken together the results presented in Tables $1-4$ show the relative basicities of the sulfoxides to be as follows:

diphenyl sulfoxide $<$ dibenzyl sulfoxide $<$ dimethyl sulfoxide

It may also be noted that there is no possibility of direct interaction between the phenyl ring and the sulfur atom in dibenzyl sulfoxide, a fact which is consistent with the sequence of the proton accepting ability found for diphenyl sulfoxide $\left[\left(\mathrm{C}_{6} \mathrm{H}_{5}\right)_{2} \mathrm{SO}\right]$ and dibenzyl sulfoxide $\left[\left(\mathrm{C}_{6} \mathrm{H}_{5}-\mathrm{CH}_{2}\right)_{2} \mathrm{SO}\right]$.

As the experimental data in Tables 1 and 2 show, the proton donor ability of various proton donors towards dibenzyl sulfoxide, as displayed in the $K$ and $-\Delta H$ values, decreases in the order: 2-naphthol $>1$-naphthol $>$ phenol $>2,2,2$-trifluoroethanol $>2,2,2$-trichloroethanol $>$ 2,2,2-tribromoethanol $>$ carbazole $>$ indole $>$ pyrrole

The $\Delta \bar{v}_{\mathrm{OH}}$ and $\Delta \bar{v}_{\mathrm{NH}}$ values also follow this same sequence, except in naphthols, where the $\Delta \bar{v}_{\mathrm{OH}}$ is greater $\left(369 \mathrm{~cm}^{-1}\right)$ for the 1-naphthol-dibenzyl sulfoxide complex than for the 2-naphthol-dibenzyl sulfoxide complex $\left(359 \mathrm{~cm}^{-1}\right)$. It is unnecessary therefore to consider the possibility of specific interactions between dibenzyl sulfoxide and the various proton donors studied.

The presented complex formation ability of phenol, 1-naphthol and 2-naphthol towards sulfuroxygen electron donors follows the acidity order of the proton donors and that of 2,2,2-trifluoroethanol follows the proton donor ability of phenol. ${ }^{4,5,19}$ Among $\mathrm{NH}$ proton donors the proton donor ability is also in agreement with the acidity order between pyrrole and indole expressed as $\mathrm{p} K_{\mathrm{a}}$ values determined in water. 6,20

Finally, the recent studies by us and earlier studies by other investigators suggest that the complex formation ability of sulfoxides resembles that of sulfinamides. ${ }^{1-7,21}$ The complex formation ability of sulfinamides is, in turn, of about the same order of magnitude as that of carboxamides. The $K$ values are $145 \mathrm{dm}^{3} \mathrm{~mol}^{-1}$ for $N, N$-dimethylacetamide-phenol and $155 \mathrm{dm}^{3} \mathrm{~mol}^{-1}$ for $N, N$ dimethylmethanesulfinamide - phenol complexes at $298.15 \mathrm{~K}$ in carbon tetrachloride. ${ }^{21,22}$ The sulfoxides are widely used as solvents, as well as extraction agents in liquid-liquid extraction or in extraction chromatography. ${ }^{23}$ It may also be worth noticing that aromatic sulfoxides like dibenzyl sulfoxide seem to be more suitable than aliphatic sulfoxides 
for the extraction of e.g. inorganic compounds due to their lower ability to form complexes as also the results presented in this paper clearly demonstrate. $^{23,24}$

Acknowledgement. The financial support by the Magnus Ehrnrooth Foundation (to P.R.), by the Finnish Academy of Science and the Research Foundation of Medica (to J.K.) is gratefully acknowledged.

\section{REFERENCES}

1. Ruostesuo, P. Finn. Chem. Lett. (1979) 202.

2. Ruostesuo, P. Finn. Chem. Lett. (1979) 206.

3. Ruostesuo, P. and Karjalainen, J. Finn. Chem. Lett. (1979) 210.

4. Ruostesuo, P. and Karjalainen, J. Acta Chem. Scand. A 33 (1979) 765.

5. Karjalainen, J. and Ruostesuo, P. Finn. Chem. Lett. (1980) 169.

6. Karjalainen, J. and Ruostesuo, P. Acta Chem. Scand. A 34 (1980) 573.

7. Ruostesuo, P. and Karjalainen, J. Spectrochim. Acta A 37 (1981) 535.

8. Saffioti, W., Nazario, G. and Gullo, I. M. de L. Ecletica Quim. 1 (1976) 59.

9. Gramstad, T. Spectrochim. Acta 19 (1963) 829.

10. Hadzi, D., Klofutar, C. and Oblak, S. J. Chem. Soc. A (1968) 905.

11. Barnard, D., Fabian, J. M. and Koch, H. P. J. Chem. Soc. (1949) 2442.

12. Cairns, T., Eglinton, G. and Gibson, D. T. Spectrochim. Acta 20 (1964) 31.

13. Biscarini, P., Galloni, G. and Ghersetti, S. Spectrochim. Acta 20 (1964) 267.

14. Augdahl, E. and Klæboe, P. Acta Chem. Scand. 18 (1964) 18.

15. Drago, R. S., Wayland, B. and Carlson, R. L. J. Am. Chem. Soc. 85 (1963) 3125.

16. Figueroa, R. H., Roig, E. and Szmant, H. H. Spectrochim. Acta 22 (1966) 1107.

17. Kivinen, A., Murto, J. and Silvennoinen, B. Acta Chem. Scand. A 28 (1974) 697.

18. Kivinen, A., Murto, J., Liljequist, S. and Vaara, S. Acta Chem. Scand. A 29 (1975) 911.

19. Bhowmik, B. B. and Basu, S. Trans. Faraday Soc. 59 (1963) 813.

20. Yagil, G. Tetrahedron 23 (1967) 2855.

21. Møllendal, H., Grundnes, J. and Klæboe, P. Spectrochim. A 24 (1968) 1669.

22. Nakano, H., Nakano, N. I. and Higuchi, T. J. Phys. Chem. 71 (1967) 3954.

23. Vlacil, F. and Adamcova, E. Collect. Czech. Chem. Commun. 43 (1978) 1606.
24. Vlacil, F. and Khanh, H. D. Collect. Czech. Chem. Commun. 44 (1979) 1918.

Received July 1, 1981. 